\title{
O perfil do gestor universitário de cooperação internacional no Brasil
}

\author{
Fernanda Geremias Leal ${ }^{1 A}$, Rafaela Ribeiro Céspedes ${ }^{B}$ e Luciane Stallivieri ${ }^{B}$ \\ ${ }^{A}$ Universidade do Estado de Santa Catarina - UDESC, Florianópolis,SC,Brasil \\ ${ }^{B}$ Universidade Federal de Santa Catarina - UFSC, Florianópolis, SC, Brasil
}

\author{
DETALHES DO ARTIGO \\ Histórico do artigo: \\ Recebido em 17 de maio de 2016 \\ Aceito em 31 de maio de 2017 \\ Disponível online em 31 de agosto de 2017 \\ Sistema de Revisão "Double Blind Review" \\ Editor científico: \\ Ilan Avrichir
}

\section{Palavras-chaves:}

Internacionalização

Cooperação internacional

Educação superior

Gestão universitária

\begin{abstract}
RESUMO
O conceito de internacionalização tem sido utilizado na educação superior como medida de qualidade e como recurso para que as universidades respondam aos desafios de um contexto global complexo. A despeito do discurso dominante de que esse processo tem transformado as estruturas universitárias, são raros os estudos que tratam da gestão da internacionalização no domínio das instituições acadêmicas e, sobretudo, dos gestores universitários de cooperação internacional. Este artigo visa a contribuir com o início dessa discussão no Brasil e se propõe a diagnosticar o perfil dos gestores de cooperação internacional das universidades públicas federais brasileiras. O recorte abrangeu 46 universidades vinculadas à Associação Brasileira de Educação Internacional (Faubai). Desenvolveu-se uma pesquisa documental nos sítios dos setores de relações internacionais dessas instituições e nos currículos Lattes de seus gestores. Os resultados apontaram para aspectos positivos como o posicionamento dos setores nas estruturas universitárias e a experiência dos atuais gestores com atividades internacionais. Também indicaram problemas como constantes mudanças na função; acúmulo de cargos e funções; formação em áreas não relacionadas à internacionalização e falta de participação em capacitações condizentes com suas atribuições. No geral, o quadro evidenciado sugere a necessidade de investimentos nessas universidades para que a internacionalização institucional ocorra em perspectiva mais ativa.
\end{abstract}

(C) 2017 Internext | ESPM. Todos os direitos reservados!

\section{INTRODUÇÃO}

O interesse e o debate acerca da internacionalização da educação superior se intensificaram no panorama global a partir da década de 1990, com a difusão da economia globalizada. Desde então, o tema tem despertado a atenção de instituições universitárias, de governos nacionais, de agências multilaterais e de organismos internacionais envolvidos com o setor educativo. O conceito tem, igualmente, se constituído como recorrente objeto de investigação científica, na expectativa de ampliar a compreensão sobre um fenômeno reconhecidamente complexo, que implica em diferentes motivações, estágios, formas de manifestação e consequências (Knight, 2004, 2015; Altbach \& Knight, 2007; Childress, 2009;
Lima \& Contel, 2011; Gacel-Ávila, 2012; Altbach \& De Wit, 2015).

Se compreendido em uma perspectiva abrangente, o processo de internacionalização universitária envolve, além de aspectos práticos como a cooperação internacional e a mobilidade acadêmica, mudanças operacionais, estruturais e pragmáticas nas instituições envolvidas, que exigem a formulação de políticas e a implementação de estratégias (Childress, 2009; Hudzik, 2011; GacelÁvila, 2012; Nafsa, 2015). Nessa concepção, ele deve integrar-se às missões institucionais e aos planejamentos estratégicos e ser apoiado pelas lideranças, pelos docentes, pelos estudantes e por 
todas as unidades de serviço e de apoio acadêmico (Hudzik, 2011; Gacel-Ávila, 2012; Nafsa, 2015).

Os gestores universitários desempenham função elementar nas decisões políticas e no desenvolvimento de planos estratégicos de internacionalização (Childress, 2009; Nafsa, 2015). Tais planos se constituem como importante recurso para a institucionalização do processo, por servirem como: roteiro para operacionalizar a internacionalização na universidade; veículo para estimular o engajamento de participantes-chave; mecanismo para explicar o significado e os objetivos da internacionalização à comunidade universitária; meio para desenvolver colaboração interdisciplinar entre os diferentes departamentos da instituição e ferramenta para levantar recursos (Childress, 2009).

A despeito do consenso de que a internacionalização tem transformado os sistemas educacionais e as estruturas universitárias - tendo se deslocado da margem para o centro do interesse institucional (Hudzik, 2011; Gao, 2014; Gacel-Ávila, 2012; Knight, 2015) - e da quantidade significativa de estudos desenvolvidos a seu respeito ${ }^{2}$, até o momento são limitadas as pesquisas que se propuseram a investigar especificamente a gestão desse processo no âmbito das universidades e, sobretudo, os perfis dos gestores universitários responsáveis pela cooperação internacional.

Diante desse quadro e do entendimento de que o desenvolvimento de processos de internacionalização significativos, ajustados às realidades e aos objetivos das universidades e dos países envolvidos, requer, entre outros aspectos, a atuação de profissionais bem capacitados na sua gestão, este artigo tem o propósito de diagnosticar o perfil do gestor de cooperação internacional das universidades públicas federais brasileiras.

Trata-se de uma pesquisa descritiva, que apresenta um panorama geral do perfil do gestor universitário de cooperação internacional no contexto de universidades públicas brasileiras e traça

\footnotetext{
2 Uma busca realizada na base de dados Scopus, em janeiro de 2017, pelos termos internationalization AND "higher education", com restrição temporal de 2000 a 2016, demonstrou um crescimento significativo de publicações sobre o tema ao longo do período. No ano 2000, a base identificou sete publicações. No ano 2016, 228.

${ }^{3}$ Buscas realizadas na base de dados Portal de Periódicos Capes, em fevereiro de 2017, pelos termos internacionalização AND
}

observações iniciais sobre um assunto inexplorado no Brasil $^{3}$. Cabe enfatizar que esse tipo de diagnóstico tem relevância, sobretudo, nos países do Sul ${ }^{4}$, que ainda enfrentam desafios estruturais em termos de acesso, equidade, qualidade e relevância (GacelÁvila, 2012) e que tendem a se inserir passivamente no contexto da internacionalização, "fornecendo cérebros, recursos financeiros e comprando produtos educacionais" dos países nos quais a internacionalização assume caráter mais ativo (Lima \& Contel, 2011, p. 16)

O recorte abrangeu as 46 universidades vinculadas à Associação Brasileira de Educação Internacional (Faubai). Desenvolveu-se uma pesquisa documental nos sítios dos setores de relações internacionais dessas instituições e nos currículos Lattes de seus respectivos gestores. O texto está organizado da seguinte maneira: após a presente introdução, apresenta-se um panorama geral a respeito da internacionalização da educação superior contemporânea. Na sequência, trata-se da gestão da internacionalização no nível institucional e do gestor universitário de cooperação internacional. O estudo segue com a exposição dos procedimentos metodológicos adotados e com a discussão e análise dos resultados obtidos. Por fim, apontam-se as considerações finais e as referências.

\section{REFERENCIAL TEÓRICO}

\subsection{Internacionalização da Educação Superior: Conceito, Oportunidades, Desafios}

As universidades sempre se constituíram como instituições internacionais: desde suas origens, atraíram professores de diferentes países para seus quadros, desenvolveram parcerias com instituições ao redor do mundo e receberam estudantes internacionais em seus campi. Foi no início dos anos 1990, entretanto, com a difusão da globalização econômica, que a cooperação internacional na educação superior expandiu-se em velocidade sem precedentes e que o termo internacionalização propriamente dito passou a ser usado. Em tais

\footnotetext{
"educação superior" AND gestor/gestão/administração não resultaram em quaisquer artigos que tratassem especificamente da gestão da internacionalização no nível institucional e tampouco do papel do gestor universitário nesse processo.

4 O Sul, aqui é compreendido "não como uma categoria geográfica, mas como o agrupamento que reúne os chamados 'países em desenvolvimento' (países de renda média e países de renda baixa)" (Leite, 2012, p. 4).
} 
referências, a internacionalização é usualmente caracterizada como medida de qualidade e como recurso para que as instituições universitárias respondam aos desafios de um contexto global complexo (Unesco Brasil, 2003; Hudzik, 2011; GacelÁvila, 2012; Altbach \& De Wit, 2015).

Apesar da popularidade da internacionalização, não há consenso sobre seu significado e tampouco existem modelos padronizados para que as universidades se internacionalizem (Knight, 2015). De fato, diversos estudos apontam para a complexidade inerente ao fenômeno e para as dificuldades de compreendê-lo em profundidade (Knight, 2004, 2015; Lima \& Contel, 2011), em parte devido à ausência de indicadores para a mensuração adequada do desempenho na internacionalização no nível institucional (Gao, 2014) e, ainda, pela multidisciplinaridade inerente ao conceito. Como Lima e Contel (2011, p. 13) argumentam, há uma "diversidade de áreas de conhecimento envolvidas nos exercícios que se propõem a entender e explicar o processo de internacionalização da Educação Superior, sinalizando que dificilmente o fenômeno poderia ser entendido numa leitura disciplinar".

De maneira geral, a internacionalização é associada a diferentes atividades conduzidas por universidades no campus e no exterior (Ewert, 2012; Gao, 2014; Stafford \& Taylor, 2016), tais como: estabelecimento de acordos/convênios internacionais, promoção da mobilidade internacional acadêmica e condução de atividades internacionais colaborativas (Knight, 2015). Os indicadores mais comumente associados à internacionalização do ensino são a mobilidade acadêmica e a internacionalização do currículo; à pesquisa, são os projetos de investigação transfronteiriços e as publicações conjuntas (Ewert, 2012).

Uma definição bastante aceita é fornecida por Knight (2004, 2015), que concebe internacionalização como o processo de integração das dimensões internacional, intercultural e global aos propósitos, às funções primárias e à entrega da educação superior nos níveis institucional e nacional. $\mathrm{Na}$ perspectiva da autora (Knight, 2004), a internacionalização precisa ser compreendida nesses dois níveis, pois ainda que o processo ocorra no âmbito das universidades, o setor educativo nacional influencia a internacionalização significativamente, por meio de financiamentos, políticas, programas e regulamentos.

Outra tendência recorrente é considerar a internacionalização como meio para um fim. Nessa ótica, ela assume valor instrumental; trata-se de uma forma para alcançar ou aprimorar objetivos acadêmicos, socioculturais, políticos ou econômicos, sendo impulsionada, portanto, por uma diversidade de motivações, que em muitos casos se complementam (Knight, 2004; Childress, 2009; Hudzik, 2011; Gacel-Ávila, 2012; Altbach \& De Wit, 2015; Muckenberger \& Miura, 2015; Seeber et al., 2016).

Em termos de objetivos acadêmicos, a internacionalização é geralmente apontada como recurso para melhoria da qualidade acadêmica; alcance de padrões e prestígio/reputação internacionais; ampliação dos horizontes acadêmicos e desenvolvimento institucional. Refere-se, ainda, a um mecanismo de preparação dos estudantes para a vida e o trabalho em um mercado global de produtos, serviços e ideias (Knight, 2004; Hudzik, 2011; Muckenberger \& Miura, 2015; Seeber et al., 2016).

A despeito das oportunidades proporcionadas pela internacionalização, comumente enfatizadas nos relatórios e artigos a seu respeito (Lima \& Maranhão, 2011), existem contradições e desafios que se manifestam nesse contexto, decorrentes, em sua maioria, da preponderância de motivações econômicas na educação superior internacional, que resulta em consequências como a diminuição do financiamento público para o setor na maioria dos países (Altbach \& Knight, 2007; Lima \& Contel, 2011; De Wit, 2011; Altbach \& De Wit, 2015; Reitz, 2017).

Fenômenos como a hegemonia do Norte no recebimento dos fluxos de mobilidade e a evasão dos cérebros impactam, sobretudo, os países do Sul, que não estão bem preparados para capitalizar sobre a criação e o uso do conhecimento (Unesco Brasil, 2003). De maneira geral, essas nações tendem a assumir caráter passivo no contexto da internacionalização e, com isso, acabam tornando-se terreno fértil para o comércio (Lima \& Contel, 2011). Seus sistemas de ensino enfrentam desafios estruturais, sobretudo em termos de acesso equidade, qualidade e relevância, mas também em relação às estruturas e à administração universitária (Gacel \& Ávila, 2008; Gacel-Ávila, 2012). 
Nesse aspecto, Gacel e Ávila (2008), em sua pesquisa sobre as condições das universidades latinoamericanas frente aos desafios da internacionalização, constatam deficiências tanto nas instituições privadas quanto públicas. No primeiro caso, a forma gerencial predominante é centralizadora, com pouca participação docente, enquanto no segundo os gestores são eleitos prioritariamente por forças políticas, o que, de modo geral, resulta em alto nível de improvisação na gestão, ao mesmo tempo em que inibe a participação da sociedade nas decisões. Gacel-Ávila (2012, p. 504, tradução nossa) complementa que os funcionários responsáveis pelas atividades internacionais tendem a apresentar baixo nível de profissionalismo e expertise, induzindo à "ausência de potencial para a concepção, desenho, implementação e promoção de políticas de estratégias de internacionalização".

O quadro evidenciado - crescente importância da internacionalização; complexidade do conceito; multiplicidade de motivações que a impulsionam; oportunidades proporcionadas às instituições e às comunidades acadêmicas; desafios emergentes que impactam principalmente o Sul - suscita o desenvolvimento de análises sobre a gestão da internacionalização no nível institucional e, especificamente, sobre os gestores responsáveis pela gestão desse processo, que desempenham função elementar no desenvolvimento de planos institucionais de internacionalização e que podem contribuir para que, no domínio da universidade, o processo ocorra em perspectiva mais ativa.

\subsection{Gestão da Internacionalização e o Papel do Gestor de Cooperação Internacional}

Apesar da quantidade significativa de estudos desenvolvidos a respeito da internacionalização, até o momento são limitadas as pesquisas que investigaram especificamente a gestão desse processo nas universidades (Said et al., 2015; Stafford \& Taylor, 2016) e, sobretudo, os perfis dos gestores universitários responsáveis pela cooperação internacional. Como Said et al. (2015, p. 82, tradução nossa) argumentam, "compreende-se que a internacionalização consolidou sua importância no mundo altamente globalizado de hoje. No entanto, existem poucas pesquisas que enfatizam o papel das lideranças na gestão desse processo". É importante reconhecer, contudo, que diversos estudos consideram a atuação de gestores e líderes institucionais como fator crítico para o sucesso ou falha da internacionalização (Nafsa, 2015; Stafford \& Taylor, 2016).

Se compreendida em perspectiva abrangente, como processo de transformação institucional, a internacionalização não implica apenas em mudanças operacionais, mas também em mudanças estruturais e pragmáticas nas instituições envolvidas. Os gestores universitários desempenham papel crucial nesse contexto e exercem influência em todas as fases do processo: conscientização, comprometimento, planejamento, operacionalização, revisão e monitoramento (Childress, 2009; Hudzik, 2011; Said et al., 2015). A esse respeito, cabe mencionar que a Association of International Educators (Nafsa) identificou as competências necessárias às equipes de direção das universidades em relação a o que considera as cinco grandes áreas da gestão da educação internacional: a) internacionalização abrangente; b) educação no exterior; c) gestão de matrículas internacionais; d) serviços para a comunidade internacional; e) competências transversais (Nafsa, 2015).

Os reitores/diretores e os setores de relações internacionais/indivíduos responsáveis pela gestão da internacionalização são considerados os participantes internos que mais influenciam o desenvolvimento do processo (internal key drivers) (IAU, 2010; Castro, Rosa \& Pinho, 2015). Essa evidência é ratificada na pesquisa empírica de Childress (2009) sobre os aspectos facilitadores e impeditivos ao desenvolvimento de planos de internacionalização em instituições universitárias.

Childress (2009) verificou que o apoio dos líderes - reitores e pró-reitores/equivalentes da área de educação internacional - é imprescindível. Eles são participantes influentes porque "com o suporte dos líderes institucionais de topo, emergem a) apoio à captação de recursos para a implementação de um plano de internacionalização e b) credibilidade para inserir componentes curriculares no plano" (Childress, 2009, p. 298, tradução nossa). A ausência do seu apoio, em contrapartida, representa um obstáculo à viabilização do processo, pois faz com que a internacionalização não se constitua como prioridade (Childress, 2009; Hudzik, 2011; Said et al, 2015).

Ainda quanto aos aspectos facilitadores e impeditivos à gestão da internacionalização, Childress (2009) identifica trocas de cargo e períodos 
de contratação de novos gestores como dificuldades. Além disso, evidencia que, nos casos em que uma liderança teve um investimento pessoal em internacionalização em sua formação, é mais provável que ele apoie o desenvolvimento de um plano de internacionalização na universidade em que atua.

Pela centralidade que assumem no processo, os gestores de cooperação internacional devem ser capazes de desempenhar uma série de funções estratégicas, tais como as levantadas por Childress (2010), Said et al. (2015), Nafsa (2015) e Stafford e Taylor (2016):

- identificar e analisar recursos e forças disponíveis para operacionalizar a internacionalização;

- interagir eficazmente com outras culturas; determinar a natureza e as formas das parcerias internacionais e estabelecer relações recíprocas com parceiros cuidadosamente selecionados;

- discernir os riscos existentes;

- reconhecer fontes alternativas para a internacionalização;

- examinar as causas dos problemas enfrentados para a institucionalização do processo;

- enfatizar as funções universitárias nos planejamentos estratégicos de internacionalização, para garantir que os interesses gerais da universidade prevaleçam aos interesses individuais das faculdades;

- avaliar estrategicamente a eficácia atual das iniciativas de internacionalização e suas perspectivas de desenvolvimento sustentável;

- antecipar quais tipos de esforços serão necessários para gestão da internacionalização no futuro.

Outra questão relevante à gestão da internacionalização é a estrutura organizacional, que deve proporcionar condições para lidar com a mudança e com os desafios do processo. Segundo Said et al. (2015), que analisaram o papel dos líderes universitários nas mudanças e nos desafios desse processo, deve haver uma unidade responsável por facilitar e administrar os assuntos relacionados à internacionalização. Childress (2009, p. 298, tradução nossa) complementa que "a estrutura organizacional descentralizada representa um obstáculo ao desenvolvimento de planos de internacionalização institucionais".

A localização dos setores de suporte às atividades internacionais, assim como suas funções, variam significativamente (Hudzik, 2011). Quando a internacionalização tem baixa prioridade na agenda institucional, eles tendem a situar-se em hierarquias baixas, geralmente reportando-se a pró-reitorias acadêmicas. Em contrapartida, quando o processo está mais incorporado às missões da universidade, esses setores tendem a assumir o caráter de próreitoria/equivalente (vice-presidency ou provost for international affairs) (Gacel-Ávila, 2012).

Relativamente às atividades dos setores de relações internacionais, enquanto alguns se limitam à gestão dos intercâmbios e ao apoio aos estudantes internacionais, outros também se responsabilizam pelo estabelecimento de parcerias com instituições estrangeiras, administram centros de línguas e estudos culturais; buscam fontes de apoio e financiamento para pesquisas e projetos no exterior e impulsionam a internacionalização do currículo no campus (Hudzik, 2011; Gacel-Ávila, 2012). É raro, contudo, que na prática esses setores sejam incluídos nos planejamentos e nas tomadas de decisão relativas às políticas de pesquisa, ensino, currículo e recursos humanos (Gacel-Ávila, 2012).

Para exercerem seu papel na internacionalização, tais setores devem estar engajados às unidades acadêmicas, de apoio e de serviço. Isso porque a internacionalização abrangente demanda o envolvimento de toda a comunidade acadêmica (Hudzik, 2011; Gacel-Ávila, 2012; Nafsa, 2015) e porque determinadas questões, como a ausência de participação dos docentes, por exemplo, trazem desafios ao desenvolvimento do processo (SAID et al., 2015), fazendo com que, em muitos casos, a intenção de internacionalizar não ultrapasse a retórica (Childress, 2009; Gacel-Ávila, 2012). Nas palavras de Gacel-Ávila (2012, p. 507, tradução nossa), "declarações feitas por autoridades educacionais sobre a importância da internacionalização são geralmente retóricas e raramente explicitam estratégias das mudanças necessárias ao desenvolvimento institucional".

Em síntese, tendo em vista a crescente complexidade da educação superior e da gestão 
Tab. 1

Instituições incluídas no estudo

\begin{tabular}{|c|c|c|}
\hline Região & $\#$ & Universidade \\
\hline \multirow[t]{7}{*}{ Norte } & 1 & Universidade Federal do Tocantins (UFT) \\
\hline & 2 & Universidade Federal do Amazonas (UFAM) \\
\hline & 3 & Universidade Federal Rural da Amazônia (UFRA) \\
\hline & 4 & Universidade Federal do Acre (UFAC) \\
\hline & 5 & Universidade Federal do Pará (UFPA) \\
\hline & 6 & Universidade Federal do Oeste do Pará (UFOPA) \\
\hline & 7 & Universidade Federal de Roraima (UFRR) \\
\hline \multirow[t]{4}{*}{ Centro-oeste } & 8 & Universidade Federal de Goiás (UFG) \\
\hline & 9 & Universidade de Brasília (UNB) \\
\hline & 10 & Universidade Federal de Mato Grosso (UFMT) \\
\hline & 11 & Universidade Federal da Grande Dourados (UFGD) \\
\hline \multirow[t]{11}{*}{ Nordeste } & 12 & Universidade Federal da Bahia (UFBA) \\
\hline & 13 & Universidade Federal do Maranhão (UFMA) \\
\hline & 14 & Universidade Federal de Pernambuco (UFPE) \\
\hline & 15 & Universidade Federal Rural de Pernambuco (UFRPE) \\
\hline & 16 & Universidade Federal do Vale do São Francisco (UNIVASF) \\
\hline & 17 & Universidade Federal do Rio Grande do Norte (UFRN) \\
\hline & 18 & Universidade Federal do Ceará (UFC) \\
\hline & 19 & Universidade Federal de Sergipe (UFS) \\
\hline & 20 & Universidade Federal da Paraíba (UFPB) \\
\hline & 21 & Universidade Federal de Campina Grande (UFCG) \\
\hline & 22 & Universidade Federal de Alagoas (UFAL) \\
\hline \multirow[t]{17}{*}{ Sudeste } & 23 & Universidade Federal de Minas Gerais (UFMG) \\
\hline & 24 & Universidade Federal de Ouro Preto (UFOP) \\
\hline & 25 & Universidade Federal de Alfenas (UNIFAL) \\
\hline & 26 & Universidade Federal de Viçosa (UFV) \\
\hline & 27 & Universidade Federal de São João Del-Rei (UFSJ) \\
\hline & 28 & Universidade Federal de Uberlândia (UFU) \\
\hline & 29 & Universidade Federal do Espírito Santo (UFES) \\
\hline & 30 & Universidade Federal de Juiz de Fora (UFJF) \\
\hline & 31 & Universidade Federal de Lavras (UFLA) \\
\hline & 32 & Universidade Federal dos Vales do Jequitinhonha e Mucuri (UFVJM) \\
\hline & 33 & Universidade Federal do Rio de Janeiro (UFRJ) \\
\hline & 34 & Universidade Federal Rural do Rio de Janeiro (UFRRJ) \\
\hline & 35 & Universidade Federal Fluminense (UFF) \\
\hline & 36 & Universidade Federal do Estado do Rio de Janeiro (UNIRIO) \\
\hline & 37 & Universidade Federal de São Paulo (UNIFESP) \\
\hline & 38 & Universidade Federal do $A B C$ (UFABC) \\
\hline & 39 & Universidade Federal de São Carlos (UFSCAR) \\
\hline \multirow{7}{*}{ Sul } & 40 & Universidade Federal do Paraná (UFPR) \\
\hline & 41 & Universidade Federal de Santa Catarina (UFSC) \\
\hline & 42 & Universidade Federal da Fronteira Sul (UFFS) \\
\hline & 43 & Universidade Federal de Pelotas (UFPEL) \\
\hline & 44 & Universidade Federal de Santa Maria (UFSM) \\
\hline & 45 & Universidade Federal do Rio Grande do Sul (UFRGS) \\
\hline & 46 & Universidade Federal do Rio Grande (FURG) \\
\hline
\end{tabular}

Source: Elaborada pelas autoras a partir de Faubai (2016).

universitária diante das demandas de internacionalização - as quais reforçam a necessidade de mudanças operacionais, estruturais e pragmáticas nas instituições envolvidas - evidenciase que os gestores responsáveis pela cooperação internacional assumem um papel elementar nesse processo, de modo que a análise do seu perfil se faz relevante.

\section{METODOLOGIA}

Em termos metodológicos, a pesquisa caracterizouse como descritiva e documental. O recorte abrangeu as 46 universidades públicas federais vinculadas à Associação Brasileira de Educação Internacional (Faubai), pelas seguintes motivações:

a) a vinculação sugere a ocorrência de pelo menos certo nível de atividade internacional na instituição; 
b) em teoria, as estruturas das universidades são mais amplas do que as dos institutos e centros de ensino, também presentes no sistema de ensino superior brasileiro;

c) as políticas governamentais de educação superior - relativas a internacionalização, por exemplo - causam maior impacto nas instituições públicas federais do que nas públicas estaduais ou privadas.

A lista das universidades contempladas pelo recorte da pesquisa encontra-se no Tabela 1 :

Em termos de coleta, os dados foram extraídos de duas bases, em janeiro de 2016:

a) sítios online dos setores de relações internacionais das universidades (dos quais foram identificados os nomes do atuais gestores de cooperação internacional, a localização dos setores na estrutura universitária, as atividades desenvolvidas e o tamanho das equipes);

b) currículos Lattes dos atuais gestores de cooperação internacional (dos quais foram identificadas as demais informações pertinentes à pesquisa).
Para fins de análise, foram estabelecidas cinco categorias a partir do referencial teórico, mas também considerando as informações que estariam disponíveis nas bases selecionadas para a coleta e, ainda, a experiência prática das autoras na internacionalização da educação superior, uma vez que poucos estudos tratam da gestão da internacionalização no nível institucional e, principalmente, do perfil do gestor universitário de cooperação internacional. Se reconhece, dessa forma, que determinados vieses das autoras podem estar presentes nas categorias de análise desenvolvidas e nas análises dos resultados.

Enfatiza-se que não foram identificadas quaisquer pesquisas que tratassem especificamente do perfil do gestor de cooperação internacional. Nesse sentido, este estudo busca apresentar um panorama geral do tema em relação às universidades públicas brasileiras, à medida que traça observações iniciais sobre um assunto inexplorado no Brasil e que poderá suscitar o desenvolvimento de outras pesquisas com recursos metodológicos alternativos.

As categorias de análise desenvolvidas e suas respectivas descrições constam no Tabela 2:

Tab. 2

Categorias de análise

\begin{tabular}{|c|c|c|}
\hline & Categoria & Descrição \\
\hline a & $\begin{array}{l}\text { Posicionamento do setor de relações } \\
\text { internacionais na estrutura universitária }\end{array}$ & $\begin{array}{l}\text { - Existência de uma unidade específica responsável por facilitar e } \\
\text { administrar os assuntos relacionados à internacionalização; } \\
\text { - Posicionamento hierárquico da unidade (pró-reitoria; secretaria etc.); } \\
\text { - Tamanho da equipe; } \\
\text { - Síntese das atividades desenvolvidas pela unidade. }\end{array}$ \\
\hline$b$ & $\begin{array}{l}\text { Tempo de ocupação do atual gestor de } \\
\text { cooperação internacional na função }\end{array}$ & - Desde quando o atual gestor ocupa a função; \\
\hline c & $\begin{array}{l}\text { Cargo do gestor de cooperação } \\
\text { internacional na instituição e acúmulo de } \\
\text { funções }\end{array}$ & $\begin{array}{l}\text { - Titulação máxima do gestor; } \\
\text { - Cargo originalmente ocupado pelo gestor na instituição (professor, técnico } \\
\text { etc.); } \\
\text { - Desempenho simultâneo de outros cargos/funções à função de gestor de } \\
\text { cooperação internacional; } \\
\text { - Relação de tais cargos/funções com a função de gestor de cooperação } \\
\text { internacional. }\end{array}$ \\
\hline$d$ & $\begin{array}{l}\text { Área de formação do gestor de cooperação } \\
\text { internacional e sua experiência pessoal } \\
\text { com atividades de natureza internacional }\end{array}$ & $\begin{array}{l}\text { - Áreas de formação do gestor (graduação, mestrado, doutorado). } \\
\text { - Experiência do gestor no exterior (pós-doutorado, estágio, intercâmbio, } \\
\text { professor visitante) ou em outras atividades de natureza internacional } \\
\text { (participação em grupo de pesquisa internacional, desenvolvimento de } \\
\text { pesquisas sobre internacionalização). }\end{array}$ \\
\hline e & $\begin{array}{l}\text { Participação do gestor de cooperação } \\
\text { internacional em capacitações relacionadas } \\
\text { à gestão da internacionalização ou à gestão } \\
\text { universitária }\end{array}$ & $\begin{array}{l}\text { - Participação do gestor em cursos de curta duração/capacitações em temas } \\
\text { relacionados à gestão da internacionalização ou à gestão universitária; } \\
\text { - Participação em eventos científicos ou técnicos sobre internacionalização. }\end{array}$ \\
\hline
\end{tabular}

Fonte: Elaborada pelas autoras. 
A análise foi feita por meio de quadros e tabelas que permitiram visualizar os dados coletados em perspectiva ampla e comparativa, bem como contrastá-los com a literatura.

Relativamente à área de formação, foram consideradas as áreas do conhecimento descritas na categorização da Coordenação de Aperfeiçoamento de Pessoal de Nível Superior (Capes, 2014). Para viabilizar a análise, nos casos em que havia formação multidisciplinar, foi considerada a área da última titulação.

Ressalva-se, por fim, que as informações presentes no currículo Lattes são fornecidas pelos próprios usuários e que determinadas informações podem não constar na plataforma. Apesar dessa limitação, verificou-se que a grande maioria dos participantes havia feito atualizações recentes em seus currículos.

\section{ANÁLISE E DISCUSSÃO}

\section{Posicionamento do setor de relações internacionais na estrutura universitária}

Relativamente à existência de unidade específica responsável por facilitar e administrar os assuntos relacionados à internacionalização da universidade, os resultados demonstraram que as estruturas de todas as instituições incluídas no recorte dispõem desse tipo de setor. Foram encontradas as seguintes nomenclaturas: a) coordenadoria / coordenação; b) assessoria / assessoria especial; c) escritório / setor / agência; d) diretoria; e) superintendência e f) secretaria / pró-reitoria.

Das 46 instituições, dez (21,73\%) têm suas atividades internacionais administradas por coordenadoria; dezesseis (34,78\%) por assessoria; duas $(4,34 \%)$ por escritório ou setor; oito $(17,39 \%)$ por diretoria; uma $(2,17 \%)$ por superintendência; oito $(17,39 \%)$ por secretaria e uma $(2,17 \%)$ por próreitoria.

Esses dados demonstram que, de fato, deve ocorrer ao menos certo nível de atividade internacional nessas instituições. Além disso, corroboram com a literatura ao apontarem que a internacionalização tem adquirido crescente participação nas estruturas universitárias (Hudzik, 2011; Gao, 2014; Gacel-Ávila, 2012; Knight, 2015).

Evidencia-se, no entanto, que o status e a abrangência do setor variam significativamente e que estruturas de maior posição hierárquica (como superintendência e secretaria/pró-reitoria) são mais raras. Os tipos mais recorrentes são assessorias, que, pela sua caracterização, tendem a reportar-se a instâncias maiores.

Nesse aspecto, pode-se relacionar a baixa posição hierárquica do setor (Said et al., 2016) e a descentralização da gestão das atividades de natureza internacional (Childress, 2009) à falta prioridade que a internacionalização assume na agenda institucional (Gacel-Ávila, 2012). Quando o processo está mais incorporado às missões universitárias, esses setores tendem a centralizar a gestão das atividades - ainda que eles estejam engajados com as unidades acadêmicas, de apoio e de serviço, inclusive através de subunidades de gestão (Hudzik, 2011) - e a posicionar-se em instâncias maiores.

Relativamente às atividades desempenhadas pelas unidades, verificou-se que elas variam entre instituições (Hudzik, 2011). Segundo as informações nos sítios online desses setores, as atividades comuns a todas foram: gestão de mobilidade internacional estudantil (incoming e outgoing e programas com bolsa) e gestão de acordos/convênios de cooperação internacional. Também foram recorrentes programas de internacionalização em casa como o apadrinhamento de estudantes internacionais. Destaca-se, ainda, que em sete instituições (15,21\%) o setor é também responsável pelas relações entre instituições nacionais, a exemplo da Universidade Federal do Oeste do Pará (UFOPA), que recebe o nome de "Assessoria de Relações Nacionais e Internacionais (ARNI)" e da Universidade Federal Rural do Rio de Janeiro (UFRRJ), que recebe o nome de "Coordenadoria de Relações Internacionais e Interinstitucionais (CORIN)".

Também se observou certo padrão nos tamanhos das equipes dos setores analisados, em média constituída de cinco/seis pessoas, sendo duas incumbidas da administração geral do setor (secretário e secretário-adjunto; diretor e vicediretor etc.). Os cargos técnicos mais recorrentes foram: assistente em administração; tradutor / intérprete e secretário-executivo.

Apesar dessas particularidades, em termos de estrutura universitária, o panorama evidenciado parece positivo, pois a existência de setores voltados à gestão da internacionalização demonstra certo 
nível de reconhecimento e de preocupação com o processo.

Nesse aspecto, pondera-se que enquanto há redução do financiamento público para o setor educativo na maioria dos países e pressões para que as universidades busquem formas alternativas de financiamento, nos últimos anos o Governo Brasileiro promoveu programas especificamente voltados à internacionalização da educação superior, como Ciência sem Fronteiras (CsF) e Idiomas sem Fronteiras (IsF) (CsF, 2016; IsF, 2016).

Além disso, disponibilizou uma rubrica específica ao fomento da internacionalização nas universidades públicas federais. A recomendação é de que tal recurso seja usado para financiar, entre outras ações, a "oferta de e/ou participação em cursos de capacitação de docentes, gestores ou técnicosadministrativos em relações internacionais na própria universidade ou em outras instituições", bem como o "pagamento de taxas de inscrição em eventos de internacionalização de IES no Brasil e no exterior" (MEC, 2015).

\section{Tempo de ocupação do atual gestor na função}

Como alguns dos atuais gestores não mencionam o exercício da função em seus currículos Lattes, não foi possível verificar desde quando eles a exercem. Dos $33(71,74 \%)$ que incluíram a informação, apenas cinco a ocupam há mais de dez anos, sendo um (3,03\%) desde 2005 e quatro $(12,12 \%)$ desde 2006. Doze $(36,36 \%)$ foram designados nos últimos cinco anos, sendo três mais recentemente: dois (6,06\%) em 2015 e um (3,03\%) em janeiro de 2016.

Esses dados sugerem que na maioria dos casos os gestores de cooperação internacional das universidades públicas federais ocupam a função por um ou dois mandatos (4 ou 8 anos), que é o tempo de vigência do mandato de um reitor. Neste último caso, provavelmente quando o reitor em exercício é reeleito, uma vez que a nomeação é feita pelo dirigente máximo, como consta, por exemplo, no Regimento Interno da Secretaria de Relações Internacionais (SINTER) da Universidade Federal de Santa Catarina (UFSC), uma das instituições incluídas no recorte da pesquisa (SINTER, 2016, p. 1): “Art. 3응 A SINTER será dirigida por um secretário, nomeado pelo reitor".

Nesse quesito, é importante observar que as trocas de cargo e os períodos de contratação de novos gestores são fatores que dificultam a gestão da internacionalização, a qual deve integrar-se às missões e aos planejamentos estratégicos da universidade e ser apoiada pelas lideranças (Childress, 2009; Hudzik, 2011; Gacel-Ávila, 2012; Nafsa, 2015). Assim, é importante que as políticas institucionais e as estratégias em andamento não sejam descontinuadas a cada quatro anos, com as mudanças dos gestores. Cabe lembrar que, em muitos casos, a intenção de internacionalizar a universidade não ultrapassa a retórica (Childress, 2009; Gacel-Ávila, 2012) e que a mudança nas prioridades institucionais pode ser um dos motivos pelos quais isso ocorra.

\section{Cargo do gestor na instituição e acúmulo de funções}

Por tratar-se de função administrativa, os gestores de cooperação internacional também ocupam um cargo efetivo nas universidades, aos quais retornam após o fim do mandato, nos casos em que optam por dedicar-se exclusivamente à função, ou que desempenham concomitantemente.

Relativamente aos cargos dos atuais gestores, a grande maioria (45 ou 97,82\%) pertence à carreira de docente do Magistério Superior. Apenas um, da Universidade Federal do Rio de Janeiro (UFRJ), é servidor técnico-administrativo, do cargo de tradutor/intérprete.

Observou-se que, em alguns casos, a função de gestor de cooperação internacional é exercida em paralelo com outras funções administrativas. A assessora da Universidade Federal do Acre (UFAC), por exemplo, também exerce a função de vice-reitora da Universidade, enquanto $\mathrm{o}$ assessor da Universidade Federal de Campina Grande (UFCG) também ocupa o cargo de coordenador geral de pósgraduação. Cabe recordar, aqui, que quando a internacionalização tem baixa prioridade na agenda institucional, os setores de relações internacionais tendem a situar-se em hierarquias baixas, geralmente reportando-se a pró-reitorias acadêmicas (GacelÁvila, 2012).

Foi recorrente, sobretudo, o acúmulo de responsabilidades relacionadas à área internacional: muitos gestores são também coordenadores dos programas CsF e IsF ou ainda coordenam outros programas internacionais. Contudo, essa não é uma regra, visto que em determinadas instituições há outras pessoas/setores específicos (vinculados aos escritórios de relações internacionais) responsáveis 
Tab. 3

Áreas do conhecimento dos gestores de cooperação internacional

\begin{tabular}{|c|c|c|c|}
\hline Grande área & Área do conhecimento & Que & dade \\
\hline \multirow{3}{*}{ Ciências Agrárias } & Ciências Agrárias I & $5(10.86 \%)$ & \multirow{3}{*}{$7(15.21 \%)$} \\
\hline & Ciência de Alimentos & $1(2.17 \%)$ & \\
\hline & Medicina Veterinária & $1(2.17 \%)$ & \\
\hline Ciências Biológicas & Ciências Biológicas II & $3(6.52 \%)$ & $3(6.52 \%)$ \\
\hline \multirow[t]{2}{*}{ Ciências da Saúde } & Enfermagem & $1(2.17 \%)$ & \multirow{2}{*}{$2(4.35 \%)$} \\
\hline & Saúde Coletiva & $1(2.17 \%)$ & \\
\hline \multirow[t]{5}{*}{ Ciências Exatas e da Terra } & Astronomia/Física & $1(2.17 \%)$ & \multirow{5}{*}{$7(15.21 \%)$} \\
\hline & Ciência da Computação & $1(2.17 \%)$ & \\
\hline & Geociências & $2(4.35 \%)$ & \\
\hline & Matemática/Probabilidade e Estatística & $2(4.35 \%)$ & \\
\hline & Química & $1(2.17 \%)$ & \\
\hline \multirow[t]{4}{*}{ Ciências Humanas } & Educação & $1(2.17 \%)$ & \multirow{4}{*}{$7(15.21 \%)$} \\
\hline & História & $2(4.35 \%)$ & \\
\hline & Psicologia & $1(2.17 \%)$ & \\
\hline & Sociologia & $3(6.52 \%)$ & \\
\hline \multirow[t]{4}{*}{ Ciências Sociais Aplicadas } & Arquitetura e Urbanismo & $2(4.35 \%)$ & \multirow{4}{*}{$5(10.87 \%)$} \\
\hline & Direito & $1(2.17 \%)$ & \\
\hline & Economia & $1(2.17 \%)$ & \\
\hline & Serviço Social & $1(2.17 \%)$ & \\
\hline \multirow[t]{3}{*}{ Engenharias } & Engenharias II & $5(10.87 \%)$ & \multirow{3}{*}{$7(15.21 \%)$} \\
\hline & Engenharias III & $1(2.17 \%)$ & \\
\hline & Engenharias IV & $1(2.17 \%)$ & \\
\hline \multirow[t]{2}{*}{ Linguística, Letras e Artes } & Letras/Linguística & $8(17.39 \%)$ & $8(17.39 \%)$ \\
\hline & Total & \multicolumn{2}{|c|}{46} \\
\hline
\end{tabular}

Fonte: Elaborada pelas autoras a partir de Capes (2014).

pela administração desses programas. $\mathrm{Na}$ Universidade Federal de Minas Gerais (UFMG), por exemplo, além do diretor e da diretora adjunta, existe uma assessora de relações internacionais para proficiência linguística.

O CsF e o IsF, diretamente coordenados por muitos gestores de cooperação internacional, são programas promovidos pelo Governo Federal com alto nível de demanda nas universidades federais. 0 CsF - programa de mobilidade internacional para estudantes brasileiros (CsF, 2016) - concedeu mais de 100.000 bolsas no período de 2010 a 2015 e exigiu a execução de diversas atividades de seus coordenadores institucionais, referentes a divulgação; pré-seleção / homologação; acompanhamento; interlocução; acompanhamento e avaliação (CsF, 2016a).

O IsF, por sua vez - programa de internacionalização em casa que atua na aplicação de testes de proficiência e na oferta de cursos presenciais e a distância (ISF, 2016) -, ocorre somente nas universidades públicas federais e encontra-se em plena implementação / expansão.
Ainda em relação ao acúmulo de funções / cargos, cabe ressaltar que todos os gestores, exceto o técnico-administrativo, continuam desempenhando atividades do cargo de docente. Chegou-se a esse entendimento porque nos seus currículos Lattes (que haviam sido atualizados em 2015 ou 2016) constavam disciplinas ministradas no momento da coleta; publicações científicas recentes; nomes de orientandos de mestrado/doutorado e participação em bancas de defesa.

Aspectos como acúmulo de funções e o fato de que todos os docentes continuam a desenvolver as atividades do seu cargo de origem parecem desfavoráveis à gestão da internacionalização, uma vez que os gestores de cooperação internacional exercem influência em todas as fases do seu desenvolvimento, sendo considerados os participantes internos que mais influenciam o processo (Castro, Rosa \& Pinho, 2015).

\section{Área de formação do gestor e sua experiência pessoal com atividades internacionais}

Todos os gestores, inclusive o técnico-administrativo, são doutores, exceto um, pró-reitor da Universidade 
Federal do Pará (UFPA), cuja titulação máxima é especialista. Esses professores pertencem às áreas do conhecimento da Tabela 3, elaborada com base na categorização da Capes (Capes, 2014). Para fins de análise, nos casos em que havia formação multidisciplinar, foi considerada a última titulação do gestor.

Conforme a Tabela 3 demonstra, os gestores de cooperação internacional pertencem a diferentes áreas do conhecimento, não necessariamente relacionadas às atividades que desenvolvem na função.

A maioria deles pertence à grande área Letras/Linguística, seguida das grandes áreas Ciências Agrárias; Ciências Exatas e da Terra; Ciências Humanas e Engenharias. As grandes áreas com menor número de gestores foram Ciências Sociais Aplicadas, seguida das Ciências Biológicas e das Ciências da Saúde. Contudo, proporcionalmente a diferença na quantidade de gestores entre as grandes áreas não é significativa.

Destaca-se, também, que cinco gestores apresentaram formação multidisciplinar em áreas relativamente associadas a atividades de cooperação internacional (Relações Internacionais; Ciências Econômicas; História; Sociologia; Ciências Sociais; Administração; Letras; Estudos Linguísticos e Linguística Aplicada), todas pertencentes às grandes áreas de Ciências Humanas; Ciências Sociais Aplicadas ou Linguística, Letras e Artes.

Acredita-se que o conhecimento em diferentes assuntos dessas áreas proporcionem condições compreender a internacionalização em perspectiva abrangente e atuar nesse contexto de forma mais crítica, sendo esta uma necessidade às universidades dos países do Sul, que tendem a inserir-se passivamente no contexto da internacionalização. Ressalva-se que diversos estudos apontam para a complexidade inerente ao fenômeno e para as dificuldades de compreendê-lo profundamente
(Knight, 2004, 2015; Lima \& Contel, 2011), em parte devido à sua multidisciplinaridade (Lima \& Contel, 2011).

O Tabela 4 especifica as instituições e a formação dos cinco gestores que apresentaram formação multidisciplinar:

Ainda nesse quesito, os dados disponíveis nos currículos Lattes sugerem que os docentes cujas áreas do conhecimento estão de alguma forma relacionadas às responsabilidades da função são aqueles que parecem ir além de suas atribuições prescritas. Tais informações indicam haver maior nível de envolvimento com o processo de internacionalização, inclusive em nível de pesquisa, por meio de publicações em periódicos e de apresentações em eventos nacionais e internacionais.

Acredita-se que essas atividades possam contribuir para a difusão da internacionalização dentro e fora da universidade e, ainda, promover a visibilidade da instituição em nível internacional, favorecendo o estabelecimento de parcerias e colaborações relevantes. Assinala-se, nesse aspecto, que uma das atribuições do gestor de cooperação internacional é determinar a natureza e as formas das parcerias internacionais e estabelecer relações recíprocas com parceiros cuidadosamente selecionados (Childress, 2010; Said et al., 2015; Nafsa, 2015; Stafford \& Taylor, 2016). Conhecimentos teóricos acerca do fenômeno podem ser úteis ao desempenho da função e ao desenvolvimento de planos institucionais, uma vez que viabilizam um entendimento mais amplo do cenário global; das oportunidades e dos desafios do processo.

$\mathrm{Na}$ Universidade Federal de Tocantins (UFT), por exemplo, a diretora, da área de Linguística Aplicada ao Ensino de Línguas, atua na linha de pesquisa "Educação superior: processo de internacionalização e desafios da globalização" e participa do projeto de

Tab. 4

Gestores de cooperação internacional com formação multidisciplinar

\begin{tabular}{cccc}
\hline Instituição & Graduação & Mestrado & Doutorado \\
\hline UFG & Relações Internacionais & Letras & Letras \\
UNB & Ciências Econômicas & Relações Internacionais Sociologia & Sociologia \\
UFGD & Relações Internacionais & História & Ciências Sociais \\
UFMG & Ciências Econômicas Administração & Estudos Linguísticos & Linguística Aplicada \\
UFSJ & Ciências Econômicas & Estudos Linguísticos & Estudos Linguísticos \\
\hline
\end{tabular}

Fonte: Elaborado pelas autoras. 
pesquisa "Processos de internacionalização das IES: um estudo de caso das políticas da UFT", além de ter exercido o cargo de coordenadora do Programa Ciência sem Fronteiras (CSF) antes de ocupar a direção do setor.

Na Universidade Federal de Goiás (UFG), o coordenador, da área de Letras, já trabalhou nas embaixadas brasileiras na Bélgica e na Costa do Marfim, atua na linha de pesquisa "Estudos Culturais", participa do projeto de extensão "Transatlantic lifelong learning: rebalancing relations", do Núcleo de Estudos Canadenses e do Programa de Iniciação Científica África.

Ainda quanto à formação dos gestores, especificamente sua experiência pessoal com atividades internacionais, verificou-se que, aparentemente, apenas nove (menos de 20\%) não tiveram experiência de estudo ou trabalho no exterior. A maioria dos que tiveram foi para fins de formação em nível de pós-graduação ou estágio (doutorado/pós-doutorado) ou, ainda, para atuação como professor visitante em universidade estrangeira, na sua área de conhecimento.

O Diretor da Universidade Federal de Minas Gerais (UFMG), por exemplo, realizou doutorado na Alemanha, foi professor visitante na Dinamarca, na Espanha, na Alemanha e na China. A Secretária da Universidade Federal do Espírito Santos (UFES), por sua vez, realizou doutorado na Inglaterra e pósdoutorado na França.

Essa experiência pessoal do gestor com atividades internacionais apresenta-se como contributiva à gestão da internacionalização. Esse pode ser um dos motivos para a sua designação à função e um indicativo de seu interesse no tema. Como Childress (2009, p. 298, tradução nossa) constata, "quando uma liderança sênior teve um investimento pessoal em internacionalização, é mais provável que ele apoie o desenvolvimento de um plano de internacionalização na universidade onde atua".

\section{Participação do gestor \\ em capacitações relacionadas à gestão da internacionalização ou à gestão universitária}

Finalmente, no que diz respeito à participação dos gestores em capacitações relacionadas às suas atribuições, de acordo com as informações constantes nos currículos Lattes, apenas 15 (32,60\%) já participaram de programas relacionados a esses temas, a exemplo dos seguintes: gestão e liderança; negociações internacionais; planejamento estratégico; redação para negócios; atualização de gestores.

Sua participação em eventos de internacionalização também é raramente mencionada, apesar de saber-se que, na prática, diversos eventos sobre o tema são realizados no exterior e que, em alguns casos - como nas conferências anuais da Nafsa e da European Association for International Education (EAIE) - a Faubai organiza delegações de universidades associadas. Dessa forma, é possível que alguns gestores tenham participado desses eventos, mas não tenham considerado prioritária a atualização dessas informações nos seus currículos.

Pondera-se, contudo, que no geral os gestores das universidades públicas latinoamericanas são eleitos prioritariamente por forças políticas (Gacel \& Ávila, 2008), o que leva ao entendimento de que não necessariamente eles estejam interessados em participar de capacitações e eventos relacionados à internacionalização.

Cabe realçar, nesse ponto, que a designação de gestores bem capacitados e sua preparação por meio de programas permanentes que propiciem seu aperfeiçoamento e sua adequação à função constituem-se como fatores positivos. No contexto das universidades públicas federais, nas quais o gestor tende a mudar com certa frequência, a capacitação do corpo técnico-administrativo é igualmente essencial. Como Gacel-Ávila (2012) aponta, na América Latina, os funcionários responsáveis pelas atividades internacionais geralmente apresentam baixo nível de profissionalismo e expertise.

Ainda que, no geral, as capacitações sobre internacionalização sejam raras no Brasil, algumas iniciativas puderam ser evidenciadas nos últimos anos, tais como: conferências anuais da Faubai; Fórum de Internacionalização da Universidade Estadual Paulista (UNESP); Seminário de Internacionalização do Currículo da Universidade do Vale do Itajaí (UNIVALI); Seminário de Internacionalização de Ensino Superior do Estado do Paraná; O Congresso Internacional "A internacionalização do conhecimento na perspectiva das Instituições de Ensino Superior do Nordeste brasileiro". Ademais, diversas associações e universidades internacionais conduzem ações nesse 
sentido: a Organização Universitária Interamericana (OUI-IOHE), por exemplo, abriga o programa "Diploma em internacionalização do ensino superior". A Universidade do Porto, por sua vez, realiza anualmente a UPorto International Staff Training Week, treinamento voltado a profissionais da área internacional das universidades de todo o mundo.

\section{CONSIDERAÇÕES FINAIS}

Este artigo se propôs a diagnosticar o perfil do gestor de cooperação internacional nas universidades públicas federais brasileiras. Desenvolveu-se uma pesquisa descritiva e documental nos sítios dos setores de relações internacionais dessas instituições e nos currículos Lattes de seus gestores. A análise viabilizou a apresentação de um panorama geral acerca do tema, bem como a exposição de observações iniciais sobre um assunto inexplorado no Brasil. Compreende-se que esse tipo de diagnóstico tem relevância, sobretudo, nos países do Sul, cujos sistemas educacionais ainda enfrentam desafios estruturais (Gacel-Ávila, 2012) e que tendem a se inserir passivamente no contexto da internacionalização (Lima \& Contel, 2011).

O recorte abrangeu as 46 universidades vinculadas à Faubai. Foram analisadas as categorias a) posicionamento do setor de relações internacionais na estrutura universitária; b) tempo de ocupação do atual gestor de cooperação internacional na função; c) cargo do gestor de cooperação internacional na instituição e acúmulo de funções; d) área de formação do gestor e sua experiência pessoal com atividades de natureza internacional; e) participação do gestor em capacitações relacionadas à gestão da internacionalização ou à gestão universitária.

O posicionamento do setor de relações internacionais na estrutura universitária e a experiência pessoal dos gestores com atividades de natureza internacional se caracterizaram como aspectos favoráveis à gestão da internacionalização nessas instituições. O primeiro, porque todas as instituições analisadas dispõem de unidade específica responsável por facilitar e administrar os assuntos relacionados à internacionalização da universidade, o que, na literatura, é considerado necessário para líder com as mudanças e com os desafios inerentes a esse processo (Childress, 2009; Said et al., 2015). O segundo, porque a grande maioria dos atuais gestores vivenciou experiências de estudo/trabalho no exterior, tais como: doutorado/pós-doutorado, professor visitante ou trabalho técnico em órgão internacional, sendo que há evidências de que experiências pessoais dos gestores com atividades internacionais suscitam seu interesse no desenvolvimento de planos de internacionalização nas universidades onde atuam (Childress, 2009).

Por outro lado, os indícios de que os gestores, na maioria dos casos, ocupam a função por poucos anos; são designados prioritariamente por forças políticas, acumulam cargos e funções; não apresentam formação em áreas relacionadas à internacionalização e dificilmente participam de capacitações sobre gestão universitária ou internacionalização, levam ao entendimento de que eles não necessariamente estão bem preparados para cumprirem o papel de facilitadores no desenvolvimento e na implementação de políticas e planos estratégicos de internacionalização, atividades através quais podem contribuir para que, no domínio da universidade, a internacionalização ocorra em perspectiva mais ativa.

A literatura aponta que a atuação de gestores e líderes institucionais se constitui como fator crítico para o sucesso ou falha da internacionalização (Nafsa, 2015; Stafford \& Taylor, 2016). Nesse sentido, ainda que as informações aqui contidas limitem-se às disponibilizadas nos sítios dos setores de relações internacionais das universidades e nos currículos Lattes de seus gestores, este estudo contribui com a ampliação de conhecimentos sobre o tema ao apresentar um panorama geral do assunto e, possivelmente, suscitar o desenvolvimento de outras pesquisas.

Compreende-se que a questão do perfil do gestor de cooperação internacional corresponde a apenas um dos necessários pontos de reflexão dessa conjuntura. Pensando-se em termos de objetivos acadêmicos, o processo de internacionalização requer ir além do aumento da mobilidade acadêmica ou da apresentação de currículos com elementos internacionais. Trata-se de melhorar a educação superior em termos de ciência, tecnologia, inovação e, principalmente, de valores e de cidadania, com interesses legítimos ao desenvolvimento dos países, formando sujeitos bem preparados para lidar com os desafios da globalização.

Considerando-se que todo processo de internacionalização se constrói e se desenvolve a 
partir da situação de cada sistema educacional, compreende-se que as universidades públicas dos países do Sul - que tendem a apresentar políticas e planos estratégicos mais fragilizados, limitações orçamentárias, estruturas inadequadas e falta de pessoal bem preparado para lidar com as atividades de internacionalização - precisam, acima de tudo, elevar seus níveis educativos por meio de estratégias e de políticas inovadoras que acompanhem as necessidades de desenvolvimento social de seus povos.

Como continuidade desta pesquisa, sugere-se: a) conhecer a percepção dos gestores de cooperação internacional acerca das funções que desempenham; b) identificar as competências essenciais para essa função e propor um perfil geral que atenda ao contexto brasileiro de internacionalização; c) analisar as estruturas universitárias e os setores de relações internacionais mais profundamente, incluindo, por exemplo, a análise dos planos institucionais de internacionalização; e d) englobar as instituições privadas na análise.

\section{REFERÊNCIAS}

- Altbach, P. \& Knight, J. (2007). The internationalization of higher education: motivations and realities. Journal of studies in international education, 11(3/4), 290-305.

- Altbach, P. \& De Wit, H. (2015). Internationalization and global tensions: lessons from history. Journal of studies in international education, 19(1), 4-10.

- Capes. (2014). Tabela de áreas do conhecimento/avaliação. Disponível em: $<$ http://www.capes.gov.br/images/stories/download/av aliacao/TabelaAreasConhecimento_072012.pdf>. Acesso em: 29 jan 2016.

- Castro, R., Rosa, M. J. \& Pinho, C. (2015). A model for stakeholders' influence on internationalization: a contribution from the Portuguese, Brazilian, and Dutch cases. Journal of studies in international education, 19(2), 160-181.

- CsF. (2016). O que é?. Disponível em: <http://www.cienciasemfronteiras.gov.br/web/csf/opro grama;jsessionid=9327F29D7F9A050283431576AB9DB8 OA>. Acesso em: 29 jan 2016.

- CsF. (2016a). Coordenadores institucionais: papel no programa. Disponível em: <http://www.cienciasemfronteiras.gov.br/web/csf/papel -no-programa>. Acesso em: 29 jan 2016.

- Childress, L. (2009). Internationalization Plans for Higher Education Institutions. Journal of Studies in International Education. 13(3), 289-309.
- Childress, L. (2010). The twenty-first century university: developing faculty engagement in internationalization. New York: Peter Lang.

- De Wit, H. (2011). Trends, issues and challenges in internationalisation of higher education. Amsterdam: Hogeschool van Amsterdam.

- Ewert, S. (2012). Higher Education Cooperation and Networks in the Baltic Sea Region: A Basis for Regionalization and Region Building? Journal of Baltic Studies, 43(1), 95-116.

- Faubai. (2016). Instituições associadas. Disponível em: <http://faubai.org.br/pt-br/instituicoes-associadas/>. Acesso em: jan 2016.

- Hudzik, J. (2011). Comprehensive internationalization: from concept to action. New York: Nafsa.

- Gacel, J. \& Ávila. (2008). Universidades latinoamericanas frente al reto de la internacionalización. Casa del Tiempo, jul, 2-8.

- Gacel-Ávila, J. (2012). Comprehensive internationalisation in Latin America. Higher education policy, 25, 493-510.

- Gao, Y. (2014). Toward a set of internationally applicable indicators for measuring university internationalization performance. Journal of studies in international education, 1-19.

- Knight, J. (2004). Internationalization remodeled: definition, approaches, and rationales. Journal of studies in international education, 5-31.

- Knight, J. (2015). International universities: misunderstandings and emerging models? Journal of Studies in International Education, 1-15.

- Leite, I. (2012). Cooperação sul-sul: conceito, história e marcos interpretativos. Observatório político sulamericano, 7(3), 1-40.

- Lima, M. \& Contel, F. (2011). Internacionalização da educação superior: nações ativas, nações passivas e a geopolítica do conhecimento. São Paulo: Alameda.

- MEC. (2015). Orientações para utilização dos recursos de apoio à Internacionalização das IFES: ação orçamentária 8282 - Subação SS29 PDU Internacionalização. MEC.

- Muckenberger, E. \& Miura, I. (2015). Motivações para a internacionalização do ensino superior: um estudo de casos múltiplos em um sistema de ensino superior confessional internacional. Arquivos analíticos de políticas educativas, 23(66), 1-26.

- Nafsa. (2015). Nafsa International Education Professional Competencies. Washington: Nafsa.

- Reitz, T. (2017). Academic hierarchies in neo-feudal capitalism: how status competition processes trust and facilitates the appropriation of knowledge. Higher education, 1-16.

- Said, H. et. al. (2015). Role of campus leadership in managing change and challenges of internationalization 
of higher education. Mediterranean journal of social sciences, 6(4), july.

- Seeber, M. et. al. (2016). Why do higher education institutions internationalize? An investigation of the multilevel determinants of internationalization rationales. Higher education, 1-18.

- Sinter. (2016). Regimento interno. Disponível em: $<$ http://sinter.ufsc.br/files/2009/10/Regimento-InternoSINTER.pdf>. Acesso em: 29 jan 2016.
- Stafford, S. \& Taylor, J. (2016). Transnational education as an internationalisation strategy: meeting the institutional management challenges. Journal of higher education policy and management, 38(6), 625-632.

- Unesco Brasil. (2003). Educação superior: reforma, mudança e internacionalização. Anais. Brasília: Unesco Brasil, Sesu/MEC.

\section{Sobre as autoras}

- Fernanda Geremias Leal é doutoranda no Programa de Pós-graduação em Administração da Universidade do Estado de Santa Catarina (UDESC). Tem o título de mestre em administração pela Universidade Federal de Santa Catarina (UFSC) e atua como secretária-executiva na Secretaria de Relações Internacionais da UFSC. Desenvolve pesquisas nas áreas de gestão universitária e internacionalização da educação superior, com foco em cooperação regional e cooperação sul-sul. Email:fernanda.leal@ufsc.br

- Rafaela Ribeiro Céspedes atua como Coordenadora de Apoio Administrativo na Secretaria de Relações Internacionais da UFSC desde 2016. Tem graduação em Secretariado Executivo Trilíngue com habilitação em português, inglês e francês e MBA em Gestão empresarial, ambos pela Universidade Estadual de Maringá, Paraná. Tem experiência em gestão da pós-graduação, intercâmbio de estudantes internacionais, internacionalização da educação superior, gestão administrativa de relações internacionais no âmbito do ensino superior.E-mail: rafaela.cespedes@ufsc.br

- Luciane Stallivieri é pesquisadora em internacionalização da educação superior e gestão da cooperação internacional no Instituto de Pesquisas e Estudos em Administração Universitária da UFSC. Está cursando pós-doutorado em Engenharia e Gestão do Conhecimento na UFSC. É doutora em Línguas Modernas pela Universidade de Salvador, Argentina, e mestre em cooperação internacional pela Universidade de São Marcos, São Paulo.E-mail: lustalliv@gmail.com 


\title{
The profile of the international cooperation university manager in Brazil
}

\author{
Fernanda Geremias Leal ${ }^{A}$, Rafaela Ribeiro Céspedes ${ }^{B}$ and Luciane Stallivieri ${ }^{B}$ \\ ${ }^{A}$ Universidade do Estado de Santa Catarina - UDESC, Florianópolis,SC,Brazil \\ ${ }^{B}$ Universidade Federal de Santa Catarina - UFSC, Florianópolis, SC, Brazil
}

\begin{tabular}{l}
\hline ARTICLE DETAILS \\
\hline Article history: \\
Received May $17^{\text {th }} 2016$ \\
Accepted May $31^{\text {th }} 2017$ \\
Available online in August $31^{\text {th }} 2017$ \\
Double Blind Review System \\
Scientific Editor \\
llan Avrichir
\end{tabular}

\section{Keywords:}

Internationalization

International cooperation

Higher education

University management

\begin{abstract}
The concept of internationalization has been used in higher education as a measure of quality and resource for universities to respond to the challenges of a complex global context. Despite the dominant discourse that internationalization has transformed university structures, there are few studies that deal with internationalization management in academic institutions and international cooperation university managers. This paper contributes to the beginning of this discussion in Brazil by studying international cooperation managers of Brazilian federal universities. The sample included 46 universities associated with the Brazilian Association of International Education (Faubai). Documentary research was carried out using the websites of the offices for international affairs and the Lattes curriculums ${ }^{5}$ of their managers. The results point to positive aspects, such as the positioning of these offices in university structures and the personal experience of current managers with international activities. They also indicated problems such as the turnover of managers; accumulation of tasks; education in areas not related to internationalization; and a lack of participation in education programs related to their responsibilities. In general, the scenario shows a need for investments in these universities so that institutional internationalization is more active.
\end{abstract}

C 2017 Internext | ESPM. All rights reserved!

Para citar este artigo:

Leal, F. G., Céspedes, R. R. \& Stallivieri, L (2017). O perfil do gestor universitário de cooperação internacional no Brasil. Internext - Revista Eletrônica de Negócios Internacionais, 12 (2), 01-16. DOI: http://dx.doi.org/10.18568/1980-4865.1221-16

Acesse este artigo em: http://dx.doi.org/10.18568/1980-4865.1221-16

\footnotetext{
${ }^{5}$ Lattes is a Brazilian virtual platform designed and maintained by the National Council for Scientific and Technological Development (CNPq). It integrates curriculums, research groups, and institutions in one information system.
} 